\title{
PRESENCIA DE MAIMÓNIDES EN UNA OBRA DE BENJAMÍN GALEMIRI: JETHRO O LA GUÍA DE LOS PERPLEJOS
}

\author{
Eduardo Thomas Dublé \\ Profesor Titular \\ Universidad de Chile \\ ethomas@linuxmail.org
}

\begin{abstract}
RESUMEN
La dramaturgia de Benjamín Galemiri se caracteriza por sus referencias a los más diversos textos y discursos de la tradición occidental. Destacan por su riqueza significativa las citas a la Biblia y otras obras vinculadas a la tradición judía. En este trabajo se estudia la intertextualidad paródica que establece su obra Jethro o la guia de los perplejos con la de Maimónides: Guia de perplejos, centrando la atención en el modo paródico de su elaboración textual.
\end{abstract}

Palabras Clave: Galemiri, Maimónides, parodia, identidad.

\begin{abstract}
The dramatic work of Benjamin Galemiri is characteristic for its references to the most different texts and discourses of the western tradition. The Bible intertextos and other works related to the Jewish tradition are outstanding for its meaningful richness. In this work the intertextuality of his play Jethro or the Guide for the Perplexed with Maimonides's: Perplexed Guide is studied, stressing the parodistic way of its text elaboration.
\end{abstract}

KEY WORDS: Galemiri, Maimónides, parody, identity.

En el panorama del teatro chileno de las últimas décadas, la crítica ha destacado la producción de Benjamin Galemiri por su calidad, originalidad y sostenido crecimiento. En efecto, desde la exitosa presentación de su obra $E l$ coordinador en el VIII Festival de Teatro del Instituto Norteamericano de Cultura el año 1993, en la que recibió los premios al Mejor Texto Teatral y a la Mejor Obra', su trayectoria muestra una intensa actividad escritural, acompañada de los

1 Además de Mejor Actuación, Mejor Diseño y Mejor Dirección. Ver datos en la página Web del autor: www,galemiri.cl 
correspondientes montajes y creciente reconocimiento nacional e internacional. La gran cantidad de premios, invitaciones a participar en actividades dentro y fuera del país, y de mesas redondas dedicadas a su obra, evidencian la buena recepción que su creatividad tiene por parte del público y de la crítica. Lo mismo puede afirmarse de las publicaciones de sus textos dramáticos, que presentan el insólito récord de tres ediciones que aspiran a presentar panoramas de su obra completa en el breve lapso de diez años ${ }^{2}$.

Cabe preguntarse por las causas de la popularidad de una obra que no es de fácil lectura; por el contrario, su extraña construcción exige al lector competencia en diversas áreas de las disciplinas humanísticas, además de mantener una actitud intelectualmente participativa.

La respuesta a esta interrogante puede buscarse en las observaciones formuladas por la crítica especializada sobre la obra de Galemiri. Los estudiosos han puesto atención en la novedad de los espacios en que instala sus mundos ficticios ${ }^{3}$ : las acciones se desarrollan en ascensores, laderas de montañas, naves espaciales, en el mar donde nadan los náufragos de un barco que se termina de hundir al fondo de la escena, en los baños de un palacio. Esta característica de la representación se relaciona con la influencia del cine en la construcción de sus textos dramáticos, y afecta directamente a la relación de éstos con el montaje escénico de las obras. Las técnicas cinematográficas imprimen dinamismo y flexibilidad al relato dramático, además de favorecer la libertad imaginativa para construir el espacio con un valor altamente simbólico. Si a estas cualidades agregamos la excelencia de los directores teatrales y actores que han intervenido en los montajes, se entiende la buena recepción, especialmente del público joven, a su producción.

Los comentaristas de la obra de Galemiri también se han referido a la solidez y calidad literaria de sus textos dramáticos. Esta percepción ha llevado incluso a postular que sus obras se recepcionan mejor al leerlas que al asistir a sus montajes escénicos, debido a su evidente orientación hacia un lector, detectable en numerosos aspectos de su elaboración, como son el trabajo estilístico de sus didascalias, la gran cantidad y variedad de referencias intertextuales y el recurso constante a la ironia y la parodia ${ }^{4}$. Estos recursos le dan a su obra una densidad humanística poco frecuente en la dramaturgia nacional.

Otro elemento que aporta a la originalidad de sus piezas teatrales es su construcción como series de monólogos enunciados por los personajes, sin la intención de obtener respuesta del

¿ A la ya mencionada Antología de 1998, siguió en 2003 Antologia esencial. Editorial Don Bosco, Santiago de Chile; en 2006, El lobby del odio, Editorial Catalonia, Santiago de Chile, e Infamante Electra. Ese discreto ego culpable. Editorial Cuarto Propio, Santiago de Chile; y en 2007, Obras completas I, Uqbar Editores, Santiago de Chile. Hay ediciones de sus obras en Francia, por la editorial Indigo.

3 Carola Oyarzún observó esta característica de las obras de Galemiri en su intervención en una mesa redonda publicada bajo el titulo de "Las dramaturgias de Galemiri", en Teatrae. $N^{\circ} 2,2000$, pp. 32-33.

4 Agustin Letelier hace algunas observaciones al respecto en "Para leer a Galemiri", prólogo a Benjamín Galemiri: El lobby del odio, Editorial Galema, Santiago de Chile, 2006. También me refiero a este aspecto en mi trabajo: "Función de las didascalias en los textos dramáticos de Benjamín Galemiri". Anales de Literatura Chilena $\mathrm{N}^{\circ} 8,2007,155-167$. 
otro, pese a su constitución formal como diálogo. Su lenguaje, conformado por estereotipos provenientes de los discursos más variados de la sociedad neocapitalista postmoderna, actualiza y renueva el modelo textual del "teatro del absurdo" de mediados del siglo pasado, y juega con la escenificación de imaginarios provenientes de diversos géneros: desde los cinematográficos hasta la tragedia griega. Esta construcción pone en relieve la elaboración artística del lenguaje dramático y acerca la obra de este autor a las de otros dramaturgos de su generación y, significativamente, a las de algunos dramaturgos emergentes ${ }^{5}$.

El desparpajo humorísticamente irreverente y transgresor de toda normativa, que anima a sus textos, es también un elemento atractivo de su dramaturgia. Y también lo es el contenido ético vehiculado por el humor paródico y rupturista ${ }^{6}$.

Deseo proponer que la intertextualidad en la obra de Galemiri no se limita a realizar una crítica de la discursividad neocapitalista postmoderna; además establece un diálogo con la tradición cultural, actualizada en sus textos por las citas a la Biblia, a pensadores como Espinoza, a la tragedia griega y al cine de Orson Welles, entre otros directores de la época de oro del arte cinematográfico. Este diálogo se lleva a cabo principalmente a través de la parodia.

La incorporación de los textos y discursos representativos del canon cultural presenta en la obra de Galemiri la doble direccionalidad propia de la parodia: una lectura que los degrada poniendo en evidencia su pérdida de sentido en los contextos de la sociedad neocapitalista postmoderna y globalizada; y otra interpretación tácita, que descubre en ellos un valor identitario; un saber al cual la parodia, junto con denunciar su anacronia, le rinde un homenaje.

La parodia de la tradición se vincula a la imagen del Padre, símbolo del poder y de la arbitrariedad de la norma tradicional. El Padre es la autoridad, pues es depositario de los discursos y procedimientos establecidos por el saber ancestral. Pero también es objeto de sospecha, al percibirlo los hijos en el contexto de las contradicciones de la postmodernidad, que reducen su normativa ética a rituales vaciados de sus valores de verdad.

5 Podria confrontarse este aspecto del estilo de Galemiri con las observaciones que hace Roberto Matamala Elorz sobre la elaboración del lenguaje en el teatro emergente chileno. V. Roberto Matamala Elorz: "Pedazos rotos de algo: La compleja enunciación en el drama de Escobar". Revista Apuntes N ${ }^{\circ} 129,2007$, pp. 87-99. Como veremos, la recurrencia de la imagen del Padre en esta dramaturgia, es una coincidencia con la obra de Galemiri.

6 Coincido con el llamado de atención de Agustín Letelier sobre el contenido filosófico de las piezas de Galemiri. Difiero de su opinión, en cambio, en cuanto considera al humor como un elemento superficial "distractor", destinado a hacer más amable dicho contenido "profundo" (prólogo citado). Pienso que la nuptura paródica, la ironía y el humor, más que "enmascarar" al pensamiento del dramaturgo, constituyen mecanismos inseparables de su búsqueda ética, que se realiza en el nivel del discurso y no puede, por lo tanto, obviarlos. 
La acción en las obras de Galemiri generalmente se construye en torno al motivo de la rebelión contra el poder paterno ${ }^{7}$, que es también el intento, por parte de los personajes, de liberarse de las normas ancestrales establecidas: religiosas, morales, intelectuales, artísticas, literarias, teatrales. La construcción de la acción, sin embargo, mantiene de obra en obra un carácter persistentemente circular, reiterándose la situación de sometimiento e inútil enfrentamiento y anulando el transcurso temporal en el mundo dramático.

La intertextualidad en la obra de Galemiri da un lugar privilegiado a los textos y discursos vinculados a la tradición cultural judía, con la cual el autor confiesa mantener una relación particularmente productiva ${ }^{8}$.

El dramaturgo ha entregado en abundantes entrevistas y textos alguna información sobre la gravitación de su historia familiar en su escritura. Se ha referido a una tradición que se remonta a sus abuelos en Esmirna, Turquia, donde pudieron educarse en el conocimiento de la Torah y del idioma francés. De allí emigraron a Chile, forzados "por las constantes purgas entre griegos y turcos, y el antisemitismo latente". En Chile, llevaron una vida dedicada al comercio y a la actividad religiosa. "Mi abuelo fue un jajan, un religioso y profundo estudioso de la Torah, una fuerte influencia para mi". "En las sinagogas era el jajan, es decir, oficiaba en cánticos". Galemiri supone que de allí heredó su madre su "pasión por el canto sefardí. Huellas de esa extraña influencia brotan en mi escritura".

No deja de sugerir, insistentemente, la gran presencia que tienen en su obra las dimensiones de la experiencia familiar cotidiana y de la memoria de la familia: su escritura es, entre otras cosas, un apasionado hurgar en esa historia ancestral.

La figura de su padre, afirma una y otra vez, está en el origen de su descubrimiento y afición por el género dramático: su lenguaje legal, propio del hombre de leyes; su ejercicio de la ley,

7 Idea propuesta por Fernanda Bezmalinovic en "La revuelta edípica como especificidad latinoamericana en cuatro obras de Galemiri", proyecto de tesis para postular al grado de Magister en Literatura con mención en Literatura Hispanoamericana y Chilena. Estudia el tema de la revuelta en la obra de este dramaturgo desde un punto de vista básicamente sicoanalítico freudiano.

8 Respecto de la relevancia de la cultura judía en su obra y escritura, son esclarecedoras las siguientes frases del autor, que la vinculan con la identidad, el temor, la culpa y la imagen del Padre: "Creo que, en esta vida hay que sentir temor. En la tradición judia (...) hay que temerle profundamente a algo; por eso los judios usan ese gorrito, que significa que uno no puede ser igual a Dios, porque hay un limite (...) soy muy culposo; caracteristica que, no obstante, se constituye en el motor que me hace funcionar: Mi padre era abogado y yo lo espiaba en sus ratos de trabajo. Él tenia la oficina en la parte baja de la casa, y al bajar, lo veía preparando los alegatos, que siempre comenzaban con la frase "no es cierto, señor $\mathrm{X}$, que la noche del crimen", a la que respondia diciendo "ino, no, no es cierto!". Esto me hizo entender que esos diálogos eran mi mundo y que por ese camino debía conducirme. Fue él quien me dio la clave acerca de lo que son los monólogos y los diálogos, y al mismo tiempo, me hizo funcionar con este motor que se mueve entre la inocencia y la culpabilidad (...) Yo soy judio, además de chileno, y el café me remite a mi familia, a mis tíos tomando café, o jugando naipes, bebiéndolo". En Eduardo Guerrero: Acto ánico: Dramaturgos en escena. Santiago, RIL Editores, 2001, 89-106. La última frase se refiere al espacio del café Tavelli, donde el dramaturgo es cliente habitual. 
manifiesto en el castigo con la correa, "símbolo del patriarca chileno", unidos a los monólogos que enunciaba mientras aplicaba el castigo, "me enseñaron lo que eran las escrituras".

El padre de Benjamín Galemiri era abogado en Traiguén. En ese pueblo, donde estuvo diez años, descubrió el cine, que constituyó su refugio, Las caracteristicas del abastecimiento cinematográfico del pueblo le significaron experimentar fuertes mezclas de repertorio, lo que influyó en su estilo hasta la actualidad: "Escribo con las reglas del cine, superpongo locaciones y géneros".

Como explica en la cita que sigue, el judaísmo para él constituye una pertenencia; y la Biblia, un modelo totalizador de la escritura, de la imaginación y del mundo:

Así como todo lo que soy viene de lo chileno, todo lo que pertenezco viene del judaísmo. Mi primera lectura y mi última lectura siempre fue y será la Biblia. La intensidad, las aventuras más sagradas y al mismo tiempo deplorables, las encuentro en la Biblia. Todo lo de pusilánime, trepidante, erótico y encendido lo encuentro en los relatos de la Torah, que para mí son permanentes, y pienso que vivimos hasta el día de hoy épocas bíblicas.

El concepto de culpa o inocencia que me invade durante el día, en el que amanezco sintiéndome culpable, y a través de las acciones y sobre todo de las palabras, intento sentirme inocente, hasta que otra vez la culpa se instala en mí, es un reflejo cultural bíblico. Pero lo bíblico sólo tiene sentido cuando hace sistema con Chile?

\section{JETHRO O LA GUIAA DE LOS PERPLEJOS (1997)}

El propio Benjamín Galemiri reconoce a esta obra como la que mayor conmoción le ha provocado su escritura. También la recuerda como la que mayor satisfacción le ha producido ver representada en escena, por la excelencia del montaje dirigido por Alejandro Goic, en el Centro Cultural de España, con la Compañia El Bufón Negro, el año 1998. Podemos deducir que es una obra entrañable para el autor.

Como sucede con toda la producción del Galemiri, el argumento parece difuminarse en el delirante montaje de imágenes y enunciados que aparecen débilmente conectados por las confusas referencias a cierto acontecer y, especialmente por vinculaciones semánticas de orden más lírico que dramático. Con todo, y como también acostumbra a suceder en sus obras, es posible construir una historia que otorga un pálido eje de construcción dramática. Su significación profunda se construye en el plano alegórico, a la luz de los intertextos.

Se trata de la historia de una familia judía en Chile, que en algunos elementos de orden cronológico y generacional puede referir a la situación del autor. Por ejemplo, la inmigración de los personajes de Aarón y Rebeca pudo suceder por el mismo tiempo que llegaron al país los abuelos 
de Benjamín Galemiri. El malestar de Rubén, como tercera generación en el país, y su fallida rebeldia cultural, no son muy distintos de la conciencia existencial que manifiesta el autor, tanto en sus obras como en las entrevistas que ha concedido. Lo mismo puede afirmarse de la angustiosa rebeldia del representante de la segunda generación, Jethro, que tiene su motivación en una crisis de identidad, expresada en el enfrentamiento con su padre, Aarón.

Estos elementos del mundo dramático se ordenan en un argumento de orden policial: alguien incendió la tienda de Aarón, el patriarca, y el Juez Jeremías está a cargo de la investigación. La abogada de Jethro, que ha sido acusado como culpable del incendio, es Débora, su mujer. El acontecer se entrega por medio de las narraciones de los personajes, quienes enuncian monólogos dirigidos al público, en los que se refieren a diversos tópicos: a las relaciones de todo típo existentes entre ellos, a la investigación del Juez Jeremías, a los antecedentes de la historia y, de manera muy destacada, al propio acto de narrarla en escena, juzgando sus méritos y desventajas literarias.

Símbolo de la imagen paterna es el espacio escénico, que la representación constituye en la tienda de Aarón, la cual alberga y se transforma en todos los otros espacios que atrae el relato de la historia de la familia. Así lo explica la voz del dramaturgo en la didascalia que inicia el texto dramático:

LA ESCENOGRAFÍA BÁSICA ES UNA TIENDA. DURANTE EL TRANSCURSO DE LA OBRA, Y A MEDIDA QUE VAN PRESENTÁNDOSE DIVERSAS SITUACIONES, LA ESCENOGRAFIA-TIENDA VA TRANSFORMÁNDOSE, POR EJEMPLO EN UN BARCO, DONDE VIENE EL INMIGRANTE AARÓN HALEVI, O EN UNA COLINA, DONDE APACIENTA OVEJAS JETHRO, UNA VENTANA POR DONDE SE PUEDEN VER PAISAJES, UNA SALA DE TRIBUNAL, UNA SINAGOGA, UNA CELDA; ES DECIR, LA TIENDA SERÁ UN OBJETO MUTABLE ESCENOGRÁFICAMENTE, COMO UN JUEGO DE MECANO, EL QUE COBIJARÁ LAS DISTINTAS LOCACIONES EN QUE VIVEN LOS PROTAGONISTAS DE ESTA AVENTURA.

DE LA MISMA MANERA QUE LA ESCENOGRAFIA ES MOVIBLE, LAS ESCENAS SON MODULARES...ES MÁS, PARECERIA ACONSEJABLE Y MUY SALUDABLE QUE, EN CADA PUESTA EN ESCENA, LA OBRA SE PRESENTE EN UN ORDEN DIFERENTE ${ }^{10}$.

La tienda del abuelo inmigrante contiene todos los espacios y tiempos de la historia familiar, constituyéndose en el símbolo de la identidad ancestral. Esta fusión de tiempos y espacios justifica el carácter modular de la representación que sugiere el autor en la didascalia. La tienda es, en consecuencia, el ámbito en que la memoria familiar se conserva y recrea mediante la narración. En ella Aarón narra su propia historia, al mismo tiempo que convoca a sus hijos Jethro y Susana:

Benjamín Galemiri: Antologia esencial. Santiago de Chile, Edebé-Editorial Don Bosco S. A., 2003, p. 364. Citaré por esta edición. 
", Por dónde empezar? Por dónde no vagué en esta persistente búsqueda... Alma errante. Renacuajo... ¿Qué esperamos? Está bien, soy yo, Aarón Halevi. En dos palabras, soy un viejo niño abandonado. (COMPÁS ERRANTE.) En Esmirna, levanté una sinagoga... En Atenas, levanté dos sinagogas, en Temuco edifiqué un par y fui siervo de Dios. Dominarse. También lo he tratado, ser feliz, lo fui, dos veces, quizá cuatro, ¿me desnudo ante ustedes?" (364).

Tres motivos de transgresión de la imagen del Padre se reiteran en la obra, combinándose para significar su crisis que, como ya señalamos, simboliza las del lenguaje y la memoria ancestrales.

De esos motivos, el más evidente es el incendio de la tienda. Jethro es investigado como sospechoso de ser el autor de este atentado, que no es sino una expresión de rebeldía contra el poder normativo de la tradición. Sin embargo, avanzando la obra nos enteramos de que Jethro tenía a su vez una tienda en el sur de Chile, que también fue quemada. Este es un índice de la circularidad temporal del mundo representado, en el que la rebeldía no es suficiente para generar un cambio. De esta circularidad del acontecer nace la condición atemporal del mundo, estancado en un acontecer reiterativo. Probablemente, el carácter "modular" de la obra, propuesto por el dramaturgo, se refiere precisamente a este modo de darse el tiempo en el mundo dramático. Si el acontecer se repite constantemente, su orden puede ser cualquiera, pues todos los sucesos son simultáneos. La situación inicial persiste invariable a través de las generaciones" ${ }^{\prime}$.

La diseminación de la imagen del Padre -y la de la Madre- en varios personajes es otro motivo que expresa su crisis como institución cultural. También las relaciones y roles familiares se vuelven dudosos en el juego narrativo de los personajes, quienes a veces reconocen mentir, como hace Susana al presentarse en su primer monólogo. El propio Aarón confiesa su angustia por tener que revelarle a su hijo Jethro que él no es su padre. Jethro, a su vez, declara haber descubierto que tanto él como su hermana Susana no son hijos de Aarón como se les había informado hasta entonces, sino del Juez Jeremias. Susana, por su parte, declara ser la madre y la amante de su hermano. La esposa de Jethro, Débora, es la imagen misma del deseo y la pasión; declara ser también hija del Juez Jeremías y haber sido amante del padre de su esposo, Aarón. Si bien Susana siente celos de Débora, ambas tienen un romance luego de enfrentarse. El hijo de Jethro y Débora, Rubén, confiesa estar enamorado de ella. Más allá de los códigos freudianos sicoanalíticos que actualizan estos motivos de incesto y de conflicto con el Padre, ellos remiten al carácter discursivo de estas imágenes. Constantemente se pone en relieve el acto de narrar y crear la historia por la enunciación narrativa de los personajes, quienes se contradicen y desmienten unos a otros, disputándose los roles en el argumento.

La disposición textual expresa la circularidad. Al final de la obra, Jethro dirige al público las mismas palabras con que Aarón la inicia: "Está bien, soy yo, Jethro Halevi, el hijo de la diestra de Aarón Halevi. En dos palabras, soy un viejo niño abandonado. (COMPÁS ERRANTE.) En Chiloé levanté una sinagoga y fui siervo de Dios. Dominarse. También lo he tratado, ser feliz, lo fui, dos veces, quizás cuatro, ¿me desnudo ante ustedes?" (425). Estas palabras las pronuncia en el Libro XXXIX y final, que se titula de la misma manera que Libro I en que las pronuncia Aarón: "¿Cuántos son los años de tus dias?" Esta frase, significativa de la simultaneidad del tiempo en el mundo representado, las repiten varios personajes a lo largo de la obra. 
En concordancia con los simbolismos de la tienda y del Padre, que remiten a la cultura judía ancestral, las nominaciones de los personajes remiten a los textos de la Torah. Su referencia opera también por inversión de los modelos originales bíblicos. La obra de Galemiri presenta en acción a una Susana incestuosa y provocativa; a un Jeremías que ha transformado su saber profético en ley anquilosante de la historia en vez de ejercerlo como anuncio de un porvenir de renovación. El lenguaje de los personajes contribuye a este efecto de extravío (del Padre, del sentido original de la norma, de la identidad) al cruzar las terminologías de la cultura ancestral con las de la globalización postmoderna.

\section{GUIA DE PERPLEJOS (1185-1200)}

La vinculación intertextual más importante para la comprensión del sentido de Jethro o la guia de los perplejos es su referencia evidente desde el título a una de las obras fundamentales de la cultura judaica: Guia de perplejos, escrita entre los años 1185 y 1200 por Maimónides (11351204), "un incomparable codificador de la legislación judía y un guía espiritual de comunidades judías del siglo XII"12. Dentro de la historia de la cultura judía, este pensador es el símbolo del amor a la verdad y a su búsqueda mediante el intelecto". de los descarriados", esta obra está destinada por su autor a exponer a sus correligionarios "las ideas verdaderas" de la religión y orientarlos hacia las normas de conducta que se desprenden de ellas. Se la considera una obra intelectualmente audaz, en la que el pensador especula teóricamente sobre la interpretación de los libros sagrados, haciendo uso independiente de la razón, cuyo ejercicio procura instituir como fundamento de la fe en la verdad revelada.

En la Introducción, al explicar los propósitos de su obra, Maimónides explica que desea "explicar el sentido de ciertos nombres que aparecen en los libros proféticos. Entre estos nombres, unos son homónimos, pero los ignorantes los toman en una sola de sus acepciones. Otros son metafóricos, y se los toma en su significación primitiva; otros, finalmente, son anfíbológicos, de manera que unas veces se los toma por apelativos y otras veces se supone que son homónimos". Pocas líneas más adelante declara que su objeto es "la ciencia de la Ley en el verdadero sentido de la palabra", y agrega:

Se propone ilustrar al hombre religioso que tiene establecida en su alma la verdad de nuestra Ley, que es perfecto en su religión y costumbres, que ha estudiado las ciencias de los filósofos y conoce sus diversos asuntos y que habiéndolo atraído y guiado la razón humana a sus dominios, está desorientado. Quiero decir, que está desorientado por el sentido literal exterior de la Ley y por lo que siempre ha entendido o se le ha dado a entender acerca de la significación de los nombres homónimos, metafóricos o anfibológicos. Esto lo tiene agitado y perplejo. ¿Se dejará guiar por su razón y rechazará lo que ha aprendido sobre esos nombres? Si obra así,

12 León Dujovne: Prólogo a Maimónides, Moisés ben Maimón: Guia de los descarriados. Tratado de Teología y Filosofia. Editorial S. Sigel; Buenos Aires, 1955. Vol. 1, p. II. Cito por esta edición.

13 Id., p. III. 
creerá que ha rechazado los fundamentos de la Ley. ¿Se atendrá a lo que ha entendido, sin dejarse llevar por la razón? Habrá dado la espalda a la razón. Se habrá alejado de ella y creerá que su religión ha sufrido daño y detrimento (Vol. I, Introducción, p. 10).

Define así a su destinatario como un hombre justo, conocedor de los textos sagrados y versado en las ciencias de su tiempo. Por otra parte, establece en el lenguaje el centro de interés de su tratado, apoyándose en la convicción de que solo una adecuada comprensión de su naturaleza y modo de significar permitirá una aproximación correcta a las Escrituras. Dicha aproximación, en su criterio, debe considerar a la alegoría como un elemento insoslayable a la hora de interpretar el verdadero significado de los Libros de la Torah:

Este tratado tiene también otro fin: explicar las muy oscuras alegorías que se encuentran en los libros de los profetas, sin que esté del todo claro que sean alegorias. Porque es asi, el ignorante y el atolondrado las toman en su sentido exterior sin ver en ellas un sentido esotérico. $Y$ aun si las examina un hombre verdaderamente instruido, ellas le traerán igualmente perplejidad, si las toma en un sentido exterior. Pero, en cuanto le hayamos explicado el sentido de la alegoría o le advirtamos que se trata de una alegoria lo habremos puesto en el buen camino y salvado de su perplejidad.

El carácter alegórico de las escrituras se explica por la gran complejidad de los misterios que ellas informan: "(...) porque nuestra facultad es insuficiente para entender en toda su realidad la más grave de las cuestiones, se ha acudido, para hablarnos de los problemas profundos de que la divina sabiduria ha juzgado conveniente hablarnos, a las alegorías, a los enigmas y a las palabras extremadamente oscuras (...)" (vol. I, p. 14). En consecuencia, dependerá de nuestra capacidad y entendimiento el grado de comprensión que obtengamos de nuestra lectura de los textos sagrados.

Importa para el estudio de la relación entre la obra de Benjamín Galemiri y Guía de los perplejos la relevancia que adquiere en este tratado el lenguaje, muy especificamente en su dimensión simbólica; pero también la importancia que Maimónides atribuye al entendimiento humano, preocupación que se relaciona estrechamente con el problema del lenguaje de las Escrituras. La inteligencia ocupa un lugar central en sus concepciones del cosmos y de la condición humana.

En efecto, este pensador instituye a la inteligencia como un verdadero eje de su Tratado, de modo que sustenta y atraviesa su cosmovisión y afecta hasta a la imagen de su lector. La inteligencia divina rige y ordena al mundo en todas sus esferas.

En su concepción, cada esfera del cosmos está regida por una inteligencia particular: la esfera humana, el mundo sublunar, está regido por el "intelecto agente", que permite a nuestro espíritu pasar "de la potencia al acto".

De las partes del alma humana que distingue Maimónides, la que caracteriza y distingue al hombre de los individuos de las especies animales, es la intelectiva:

A todos los hombres les es dada esta facultad, que es intelecto primario, hylico, y no se encuentra en los individuos de las demás especies animales. Por obra de ella puede el hombre 
vivir, subvenir a sus necesidades, ampararse de las inclemencias del medio físico, prever con anticipación los hechos, para eludir los que pudieran serle funestos. Merced a ella el hombre vive y convive con sus semejantes; sin la sociedad es inconcebible la existencia del individuo. Necesita de ella, sin ella perecería. Esa facultad racional, ese intelecto primario, está en el cuerpo, unido a él y lo gobierna. El intelecto hylico, primario, nace con el hombre y es individual. Es una "predisposición", que, según la interpretación de Ajad Haam, "torna al hombre capaz de aprehender las cosas inteligibles y que necesariamente se deteriora si queda toda su vida en su estado primero, esto es, de predisposición no traducida en acto". Si el hombre emplea esta facultad procurando entender efectivamente las cosas inteligibles, su intelecto pasa de la potencia al acto, logra una existencia propia, permanente, como las percepciones que ha alcanzado y que forman con él una sola cosa; se torna intelecto adquirido, distinto del cuerpo y que vive y existe eternamente "como las otras Inteligencias separadas" (Dujovne, p. IX).

De acuerdo con este planteamiento, la misión del hombre es activar su intelecto para alcanzar la perfección. Por el ejercicio de su facultad intelectiva, racional, que es la parte de su alma que participa de la inteligencia divina, el ser humano tiene que dedicar todos sus esfuerzos a la empresa de alcanzar el entendimiento de la verdad presente en los elementos inteligibles del mundo que habitamos. Existen grados de realización de este objetivo trascendente por parte de los hombres, dependiendo de la capacidad de cada individuo. Sobre esta base de la capacidad intelectual individual, se establece una escala jerárquica de la humanidad en cuyo nivel más alto se encuentra el profeta, máxima posibilidad de perfección y virtud a la que puede aspirar el género humano:

(...) el derrame divino, que encontramos unido a la especie humana, esto es, el intelecto humano, es algo que sólo tiene existencia por las inteligencias individuales, es decir, por aquello que, (de la Inteligencia divina) se ha esparcido sobre Zaide, sobre Amr, sobre Jaled, y Becr.

Siendo esto así, se sigue (...) que cuanto más participe un individuo humano de ese derrame en razón de su materia (más o menos) predispuesta y de su ejercicio, tanto más protegido estará por la Providencia, si es verdad, como ya lo dije, que la Providencia depende de la Inteligencia. La Providencia divina no velará, pues, de una manera uniforme sobre todos los individuos de la especie humana; al contrario, protegerá a unos más que a otros, a medida que su perfección humana sea más o menos grande. De esta reflexión se sigue necesariamente, que la Providencia velará con mucho cuidado sobre los profetas y variará de acuerdo al rango que éstos ocupen en la profecía. Igualmente, velará sobre los hombres superiores y los virtuosos, según su grado de superioridad y virtudes, pues es el grado del derrame de la inteligencia divina lo que ha hecho hablar a los profetas, ha dirigido las acciones de los hombres virtuosos o ha perfeccionado, por la ciencia, los conocimientos de los hombres superiores. En cuanto a los hombres ignorantes y pecadores, privados de ese derrame, se encuentran en un estado despreciable y son puestos en el rango de las otras especies de animales: Es semejante a las bestias privadas de la palabra (Salmos, XLIX, 13 y 21); por eso matarlos ha sido considerado como cosa ligera, y hasta ha sido ordenado para el bien público (Tercera Parte, Capítulo XVIII, p. 91).

Este es un principio religioso fundamental, concluye Maimónides: la Providencia, que depende de la Inteligencia divina, protege a los hombres según su mérito individual. La condición humana es libre. Su libertad debe ejercerla en el cumplimiento de las leyes de Dios, que provienen de su sabiduría, y así responder a la finalidad misma de la creación, que no es otra que 
producir al ser más perfecto posible para la realidad humana: el hombre que posee el "intelecto adquirido".

El ser humano debe orientar su vida por el objetivo de "plasmar con su alma lo inteligible"; solo asi logrará poseer la sabiduria que "acrecienta su fuerza interior y de un grado de vida despreciable lo eleva a una dignidad de vida honorable".

\section{"JETHRO O LA GUIAA DE LOS PERPLEJOS" Y "GUÍA DE PERPLEJOS"}

Un elemento en común de ambas obras es haber sido escritas en épocas de crisis y transición. El eminente sabio judío escribe en los albores del renacimiento humanista, que constituirá, como sabemos, un quiebre profundo en la cultura occidental, afectando a los sistemas de creencias que la fundamentaban y, por lo tanto, integralmente a su concepción del mundo. El dramaturgo chileno produce su obra en los contextos de la postmodernidad, que constituye una ruptura histórica y cultural solamente comparable con la que experimentó la sociedad del Renacimiento. No es extraño, por lo tanto, que Benjamín Galemiri adopte como referente el texto del pensador judío.

Guia de perplejos está destinada a afirmar la fe en la doctrina religiosa tradicional, para los hombres sabios y virtuosos que "vacilaban" bajo el influjo de las contradicciones entre el emergente raciocinio filosófico y científico, y los contenidos de la Ley tradicional, en los contextos del pensamiento del siglo XII. Identifica a su destinatario como un correligionario víctima de desconcierto en medio de las transformaciones culturales, en riesgo de sufrir extravio intelectual y "descarriarse", apartándose de la doctrina verdadera. Su estudio está dedicado, en consecuencia, a "la ciencia de la Ley en el verdadero sentido de la palabra"; y postula una aproximación correcta a los textos de la Torah, que profundice en su sentido más allá de los errores a que pueda conducir una interpretación ingenuamente literal, que permanezca en la superficie del texto.

Un planteamiento así tiene que haber sido atractivo para un dramaturgo como Galemiri. No solamente por la relación obvia entre la obra de Maimónides y la figura del Padre poseedor de la palabra y la Ley, que tanto insiste en destacar como una de las obsesiones temáticas que recorren su escritura. Pienso que el planteamiento del sabio respecto del lenguaje de las Escrituras como un texto en clave simbólica, constituyente de un desafio para el lector que desee acceder a las verdades más profundas, debe haberle seducido, por su evidente proximidad al concepto del lenguaje que sustenta en su propia producción. Las piezas de Galemiri tienen en el lenguaje el centro de interés; y su clave en la construcción alegórica -no limitada a una lectura única "verdadera", sino abierta a multiplicidad de interpretaciones, de acuerdo al concepto de Walter Benjamin-, basada en la yuxtaposición y cruce de infinidad de discursos y citas textuales.

De acuerdo con lo anterior, a la hora de confrontar la obra de Galemiri con el texto de Maimónides para indagar en el sentido de su incorporación como hipotexto sustentador de su construcción, es posible descubrir una gran cantidad de coincidencias sugerentes de variadas significaciones, ya sea por afinidad o por divergencias. Una de ellas corresponde a la concepción del lenguaje, que acabo de comentar. Ambos coinciden en considerar a la palabra como la clave de los textos y acceso a la revelación del sentido verdadero. Consecuentemente, otra coincidencia 
se descubre en la concepción ética de la función del escritor y de la práctica lectora. El pensador judío del siglo XIl busca guiar al hombre culto a una lectura correcta de los textos sagrados, conducente a un camino hacia la verdad y la virtud. El dramaturgo chileno postmoderno, en una opción que lo aparta del nihilismo escéptico predominante entre sus coetáneos postmodernos, concibe la función del artista como fundamentalmente ética y de conocimiento, vinculada a la interrogante por la posibilidad del sentido en el mundo. Tanta es la convicción del dramaturgo sobre esta función del artista, que el año 2001 atribuyó derechamente a la pérdida de esta noción del lenguaje artístico por parte de nuestros dramaturgos y hombres de teatro, la situación de precariedad que muchos veían en la producción nacional más joven:

"Yo creo que hay que volver a la mentada pregunta del ser, como dice mi amigo Heidegger, y no solamente en términos filosóficos, sino que en todos los términos del quehacer cotidiano. Creo también que toda obra de arte debe tender hacia una conducta moral, que no es solamente el bien y el mal. A mí me gustaría que la dramaturgia del siglo XXI develara la proposíción y construcción de un nuevo mundọ; sin embargo, veo a estos jóvenes y creativos autores un poco desorientados moralmente ${ }^{14}$.

Aspira Benjamín Galemiri a un teatro que transmita un contenido filosófico al espectador. De acuerdo con esta concepción, se dirige al espectador culto, elitismo en el que coincide con su referente del siglo XII:

E.G.: Entonces, hay que colocar, al comienzo de la función, un letrero que diga: "Prohibido para menores de treinta".

B.G.: No. El cartel tendria que decir: "Se exige haber leído a Joyce"'s.

Como la de Maimónides, la obra de Galemiri se ofrece como una "Guía", desde su título, para individuos desorientados en una sociedad en crisis. Mientras Maimónides ordena, codifica y consolida con su lectura interpretativa de los textos sagrados el valor de verdad de Ley tradicional, apoyándose en la polisemia y carácter alegórico de los textos sagrados, el chileno invierte esta orientación, para dar cuenta de la "perplejidad" del individuo postmoderno, que se encuentra en abandono, desvalido de cualquier criterio de verdad.

El sentido de su ofrecerse como "Gufa", de acuerdo con este planteamiento, es profundamente diferente de su prestigioso y venerable modelo. A la rotunda seguridad con que expone su interpretación de las Escrituras el maestro del siglo XII, aquí se opone la angustiada inseguridad de un autor latinoamericano de fines del siglo XX, manifiesta en la voz del dramaturgo presente en las didascalias y enmascarada detrás de los monólogos y simulacros de diálogo que enuncian los personajes.

14 Eduardo Guerrero: Acto único, op. cit., p. 105.

is Id., p. 99. 
La vinculación transtextual con el Tratado de Maimónides se realiza básicamente desde la parodia -entendida ésta al modo de Bajtin-, relacionándose con él por medio de la ironia, invirtiendo sus términos para poner de relieve su distanciamiento y critica.

Sabemos que todo texto parodiante se establece como paralelo al ante-texto parodiado, deformándolo y exigiendo al lector o espectador que establezca las relaciones entre ambos; esto es, que reconozca las citas y reconstituya el texto original actualizado y recreado en la cita:

Entre palabra parodiante y palabra parodiada existe un enfrentamiento de valoraciones, chocan entre si horizontes semánticos e ideológicos decididamente hostiles: el autor toma la palabra ajena para mostrar su falsedad, la relatividad de su sentido, sus vanas pretensiones de convertirse en discurso absoluto ${ }^{16}$.

Sin embargo, parece haber acuerdo en reconocer también en la parodia, simultáneo al destronamiento carnavalesco que le es propio, un contenido de homenaje al discurso parodiado:

Como la risa carnavalesca, la parodia es ambivalente, tiene un doble sentido: se orienta hacia la destrucción de la palabra y de los acentos ajenos, y simultáneamente opera la "resurrección" de esa palabra, busca hacerla renacer como una palabra nueva (esta ambivalencia esencial se habría perdido en las formas modernas del género, por lo menos a partir del romanticismo) ${ }^{17}$.

En el caso del texto que estamos analizando, la parodia surge del contraste entre los discursos y textos que cita y entrecruza la obra dramática. Los personajes aparecen en abandono existencial, incapaces de comprender sus situaciones y de comunicarse entre ellos. Su aislamiento y desconcierto se hacen evidentes en la ausencia de diálogo real. Si formalmente sus enunciados aparecen muchas veces dispuestos como en un diálogo propio del drama tradicional, su contenido demuestra absoluta incapacidad para hacerse cargo de las perspectivas ajenas y, mucho menos, modificar la propia ante la fuerza de los argumentos del interlocutor. Los enunciados de los personajes de Galemiri solo se relacionan indirectamente, a la luz del entramado total del texto, aludiendo siempre a situaciones de pugnas por el poder en sus diferentes formas. Todo esto distancia al mundo dramático de este autor respecto del universo de Maimónides, sólidamente asentado en la capacidad del entendimiento humano para acceder a la verdad absoluta contenida en las Escrituras.

En el mundo dramático de Galemiri, hay escaso lugar para el erotismo y el amor; los personajes se relacionan por el hedonismo, y el sexo se ejerce como instrumento para el poder. La legalidad de este universo imposibilita una relación auténtica de maestro a discípulo, como la que presenta Guia de perplejos entre Maimónides y el joven a quien el sabio dirige su discurso con noble función pedagógica.

i6 Pampa Olga Arán: Nuevo diccionario de la teoria de Mijail Bajtín. Córdoba, Ferreira Editor, 2006, p. 212.

$17 \quad$ Id., p. 214. 
Las relaciones transtextuales que van generando los enunciados de los personajes y los del dramaturgo en las didascalias, constituyen la verdadera vía de acceso al sentido real de la pieza, que debe ser construido por el lector/espectador en su acto de recepción. Por lo tanto, la obra exige el conocimiento de las referencias intertextuales, demandando al receptor una participación activa. Este es el fundamento de la humorística proposición de Galemiri, de incluir en el programa de sus obras la exigencia de "haber leído a Joyce".

La intertextualidad opera invariablemente, como ya adverti, de modo paródico y su función consiste en develar el real contenido de los discursos tradicionales, en cuanto vehiculos enmascarados del poder. Los elementos de la tradición judaica aparecen carnavalizados por medio de su entrecruce con los discursos de la cultura postmoderna. Este recurso los vacía de su contenido original, reduciéndolos al mismo valor de cambio que tienen las jergas del mundo neocapitalista globalizado: signos de consumo, estatus y, en definitiva, dominio.

La figura del Padre simboliza a la cultura ancestral, en su dimensión de la Ley heredada e impuesta. En la percepción de los personajes, se disemina en por lo menos dos figuras: Aarón, padre de Jethro, marido de Rebeca y abuelo de Rubén; y el sabio juez Jeremías.

La relación conflictiva con el Padre queda de manifiesto en el siguiente monólogo de Jethro, que denuncia la carencia de libre albedrío en una historia familiar congelada por la autoridad de la tradición. Por otra parte, este monólogo participa de la constante autorreferencialidad de los enunciados de los personajes, que invariablemente reflexionan sobre su acción de narrar la historia de la familia, apelando con sus comentarios al público. Jethro expresa disconformidad con la historia que narra, sugiriendo a los espectadores otras posibilidades para su desarrollo:

JETHRO: Apaciento ovejas...No es una mala profesión. Heredé este oficio en forma directa desde mi abuelo hasta mis archiancestros, en tierra de Canaán. Sólo que ahora lo hago en el extremo sur de Chile... No crean que siempre fui ovejero. Indudablemente, hasta hace poco era químico. Esta será una historia triste... No sê si quieren seguir presenciándola... Aún es tiempo, recuerden que hay otras propuestas... ¿No me creen? ¿Piensan que nuevamente reirán mucho? (AQUELLA VENERABLE CALAMIDAD.) ¿Me creéis? I said, químico. ¿Os gusta como profesión? (...) Vamos al meollo de la cuestión. Aquí va. (ARREBATO DEPLORABLE.) Descubrí que mi padre Aarón no es mi padre. ¿Qué tal...? ¿Bellisima intriga, no? La madre de todas las intrigas a mi entender... (LAUDABLE COSTUMBRE.) Normalmente son los hijos los que no saben. Ahora es él. Debo contarle a mi padre que no es mi progenitor... (ENGAÑOSA PRUDENCIA.) La cosa es harto complicada. Verán: conocí a mi verdadero padre. ¿Vieron <<Zorba, el Griego $\gg$ ? Bueno, mi padre es igual a Anthony Quinn. Digo mi verdadero padre, el juez Jeremías. Estoy enamorado de mi padre biológico. Y no siento nada especial por mi padre adoptado, que se ha ocupado por mi ya más de cuarenta años. Es bien imbécil esta historia, pero es así... (366-367).

El monólogo de Jethro invierte el motivo desarrollado poco antes por el propio Aarón, que ha expresado su angustia por tener que revelarle a sus hijos, Jethro y Susana, que él no es su padre sino su tío, aunque confiesa : "ya ni lo recuerdo". El único que posee la verdad es "el Juez. Jeremias... el sabio Jeremias", quien, según informan los personajes en varias ocasiones, "tiene todo escrito". Los roles de la historia, en consecuencia, están prefijados por la escritura de Jeremías y 
asignados de antemano a los personajes, pero son dudosos. Poco más adelante, Aarón reconoce desconocer totalmente a su hijo, pues no sabe a ciencia cierta quién es, realmente:

"Quién es Jethro? ¿Un bueno a tiempo completo? ¿Un malo a full time? ¿Un hippie a full time? Ya nadie es a full time hoy en día... En esta asquerosa cultura hibrida, todos son un poco todo... ¿Quién es Jethro? (374).

La figura del juez Jeremías, a quien se identifica como sabio, único conocedor de la verdadera identidad de Jethro y, en general, de la verdad, es el encargado de la investigación del atentado contra la tienda de Aarón. Tiene a Jethro en prisión, sometiéndolo a juicio como sospechoso de un acto de rebeldia culpable. Es el símbolo de la Ley.

En muchos momentos, los personajes, que como hemos comprobado, corrientemente se dirigen al público, apelan a otro destinatario de sus monólogos, identificándolo como un juez o jurado, como si toda la obra desarrollara una declaración en los contextos de un juicio ${ }^{18}$.

Todos estos elementos del texto permiten identificar, en el plano simbólico, a la figura del juez y sabio Jeremías con la del sabio Maimónides, máximo representante de la Ley tradicional, atraído a la obra por el título, que sugiere la relación intertextual con su Tratado.

En la obra de Galemiri, los personajes invierten la situación comunicativa de Guia de perplejos, en la que el sabio se dirige a su discípulo Rabi José, para orientarlo en la verdad de la Ley. Ellos se dirigen al público, pero tambiên a la figura representativa de la Ley, reconociendo los contextos de un juicio y la presencia de un jurado. El motivo de la culpa, por lo tanto, se encuentra tras todos sus enunciados; y su culpabilidad deriva de su desorientación rebelde respecto de la normativa moral tradicional.

La parodización de la figura del sabio se ejerce por todo este conjunto de inversiones que realiza la obra de Galemiri respecto de Guia de perplejos. Se extrema hasta alcanzar dimensiones carnavalescas en enunciados como el de Susana en el monólogo citado (V. nota 18), y el de Jethro, quien lo identifica con imágenes populares de la cinematografia, y reconoce una atracción sensual que lo motiva a preferirlo como progenitor.

El rechazo de Aarón a la "asquerosa cultura híbrida" actual, vincula la imagen del Padre con una actitud de rechazo del mestizaje cultural. Por lo tanto, el Padre y todos los símbolos que se articulan en torno a su figura (tienda, juez, Ley, entre otros), son portadores de un mandato ancestral de conservar la pureza de la cultura tradicional. Irónicamente, la utilización que hace Aarón del término "full time", indica el influjo de la globalización en su lenguaje.

18 AARÓN: (... ¿ ¿Cuántas veces troqué mi propia felicidad por la suya? Anulo. Anulo este comentario. Por favor señores del jurado, hagan caso omiso a ese comentario (368).

SUSANA: (...) Señor juez, interrógueme primero, comience el proceso conmigo, atrévase, usted, teriblemente bello, espantosamente sexy, con esa sien plateada, la sonrisa maligna, la caridad perfecta, atributos de padre (368). 
La carencia de liberiad se simboliza en la imagen de Jethro en el calabozo, interrogado por su abogado, que es Débora, su mujer; y se ejemplifica en el rechazo familiar que sufrió su relación con ella: "Luego amé a esa joven moabita, la que mi padre odiaba con toda su alma... ¿o era mi madre la que la odiaba?" (377). Esta prohibición se motiva en razones de clase, como revelan las siguientes palabras del mismo Jethro: "No amarás a tu hermana, está bien, lo entiendo, no amarás a Débora, la mesonera de la Esso, ¡eso no lo entiendo!" (379) ${ }^{19}$.

En el plano simbólico, es significativo del enclaustramiento que experimentan los personajes el motivo del incesto, que recorre toda la obra, como indicio de un mundo cerrado. Acompaña a este motivo el permanente cuestionamiento y relativización de los parentescos y relaciones amorosas que declaran en la escena. Las siguientes palabras de Susana son un buen ejemplo:

SUSANA: Soy hermana gemela de Jethro. A mi me toca revelarle a Jethro que no soy su hermana, aunque eso ya lo sospecha. Pero lo que no espera saber es que soy su madre. ¿Se acordaron de Jack Nicholson? ¿Sí...? Perfecto, esa es la idea... ¿piensan que es mentira? ¿Eso piensan de mi? ¿En serio? Está bien, it's a lie. A fucking lie. Pero como carta de presentación, no estuve nada de mal, eh? (...) ¿Es mi hijo? ¿Es mi padre? ¿Es mi hermano? ¿Para qué complico esta historia? ¿Amor entre hermanos? Cuando a él le gritan, a mi me gritan (367-368).

Las frecuentes alusiones de los personajes a su propio acto de narrar y organizar la representación escénica, articulan con sus también frecuentes negaciones de la realidad que ellos mismos han contribuido a construir con sus enunciados. La credibilidad del mundo desplegado por la representación escénica, en consecuencia, es precaria, y a este efecto aportan, también, las intervenciones irónicas del dramaturgo en las didascalias. Todos estos elementos inciden en la actualización del tópico del "gran teatro del mundo", como fundamento de la realidad representada. Los personajes son farsantes y el mundo es un teatro: un constante representar. El sentido que cobra este tópico se refiere al conflicto de los personajes, que consiste en su imposibilidad de escoger sus roles y controlar la historia, puesto que ya están prefijados por los escritos del juez Jeremías.

También la Madre es un rol presente en la pieza de Galemiri, con funciones equivalentes a las del Padre. Rebeca presiona a sus hijos Jethro y Susana, con chantajes emocionales e intrigas. A su modo, les transmite la cultura tradicional, formulándola como sistemas de roles prefijados y portadores de restricciones y culpas:

19 Esta protesta de Jethro se relaciona también con el carácter limitante de los programas de vida impucstos por la burguesia, asumidos por su familia, y que él siente ajenos. Puede citarse al respecto la escena del Libro $X I$, subtitulada: "Pugna constante". La didascalia indica quc: "AARÓN OBSERVA DESDE SU TIENDA. COMO JETHRO Y DEBBORA HACEN EL AMOR". Jethro pronuncia estas palabras dirigidas a su padre: "¿Cómo? ¿Qué hice mal...? ¿Qué? Padre, ¿pocos son 684 puntos para vos? ¿Y qué? ¡Vos me empujasteis a ese sucio abismo! Es vuestra guerra, no la mía. ¡Son otros los combates que quiero pelear...! Es vuestra guerra, madre, vuestra guerra, madre. Vuélvete del ardor de tu ira y arrepiéntete de cste mal contra tu pueblo... ¿Qué yerro? ¿Apartado del camino... Which is the right way, can you tell me? ¿Merezco abominación? Esta vez... ¿Qué hice mal, qué? ¿Me apedrearán?"' (378). 
REBECA: (...) Si, arrodillese, hijo mio, pida perdón una y mil veces cien, llore, reconozca sus errores, diga conmigo: Baruj Atá Adonai, bendito eres tủ... Y diga, ponga la mezuzá en su puerta, celebre el dia de la salida de Egipto... Coma matzá y ore el Shemá Israel. ¿Qué más me gustaria que fuera Jethro como hijo? ¿Por qué no me refiero también a Susana? ¿Soy la típica madre prendada del hijo varón? (MADRE FACINEROSA.) Es extraño. Susana nunca fue buena consejera... hija extraviada... ¿A quién amo, francamente? (MADRE PRERROMÁNTICA.) ¿Necesitamos una escena madre-hija? (MADRE VELEIDOSA.) ¿Sí? ¿No aún? De acuerdo. Más adelante veremos. (MADRE VILLANA.) Esperen. Fui testigo de ciertas cosas inauditas. ¿Amor entre hermanos? Conocimiento carnal. Pirata. Acongojar. Petite méchante (375).

\section{CONCLUSIÓN: QUE LA BIBLIA SEAAHORA}

Uno de los aspectos más interesantes de la obra de Benjamin Galemiri se encuentra en su elaboración de los intertextos. Su gran riqueza de referencias literarias y culturales distingue a su producción dramática dentro de nuestro medio artístico y literario por su capacidad de abrir perspectivas novedosas sobre los problemas actuales de la sociedad.

Entre los intertextos más usuales de sus piezas dramáticas destacan los referentes a textos fundamentales de la tradición judaica, con los que el dramaturgo chileno mantiene un importante nexo identitario, no exento de conflictos, según su propia confesión.

La obra a que destiné este trabajo es una de las más queridas por el autor, de acuerdo a sus propias declaraciones. En ella la tradición judía ocupa un lugar central. Aparte de los nombres de los personajes y la mención de fiestas y ritos pertenecientes a esa cultura, la pieza representa la historia de una familia de judíos inmigrantes en Chile, y centra su atención en los problemas identitarios de sus miembros, producidos por las tensiones entre los códigos que rigen su cultura ancestral y los nuevos contextos en el Chile contemporáneo.

El recurso más destacado para expresar estos conflictos consiste en la parodización del texto Guia de perplejos, a cuyos discurso y autor identifica con la imagen simbólica del Padre poseedor de la verdad, del lenguaje y de la Ley. Lo identifica simbólicamente con el poder.

Parodiza la obra de Maimónides mediante la inversión de sus contenidos y caracteristicas, cruzándolos con géneros y discursos de muy diferente orden que, a su vez, están parodiados. Si Guia de perplejos es un tratado, la obra de Galemiri es una obra teatral, pero que no está dispuesta en actos ni escenas, sino en "Libros" con títulos y textos descriptivos de su contenido, de acuerdo con formas tradicionales del relato y de otros géneros ajenos al drama. Los recursos paródicos utilizados en Jethro o la guía de los perplejos develan la inoperancia del Tratado de Maimónides en los contextos de la cultura postmoderna actual.

En general, la parodia denuncia la condición de instrumento del poder represivo que afecta a los discursos tradicionales; y pone en evidencia sus efectos obstructores del cambio histórico, que genera sentimientos de rebeldia y frustración en las generaciones de inmigrantes más jóvenes. 
Por otro lado, implícita en la parodia es posible reconocer un homenaje al sabio del siglo XII, en quien indudablemente se reconoce, por contraste con las degradadas condiciones del mundo postmoderno representado en la pieza, la noble altura de un hombre que dedicó su existencia a la búsqueda de la verdad y la virtud.

Puede afirmarse, en consecuencia, que la ácida ironía de Jethro o la guía de los perplejos, además de expresar escepticismo ante las pretensiones de verdad absoluta de los discursos de la tradición, descubre un valor en los fundamentos éticos de una vida orientada por la fe en la inteligencia; esto es, en la capacidad humana de conocer y comprender la realidad esencial.

El sentido último de la referencia intertextual de la obra de Galemiri a la de Maimónides, consiste en la afirmación de la posibilidad utópica de un mundo que se renueve desde Ja creación de su propio lenguaje; un mundo que, teniendo a la cultura ancestral como un referente, "sea bíblico él mismo":

Nosotros vivimos épocas bíblicas; la época biblica es ahora. Todo lo bueno nos está pasando ahora, y todo lo malo nos está pasando ahora también. No es necesario mirar la historia para transportarse a situaciones de exaltación, porque estamos permanentemente en crisis. Yo estoy invitando a trabajar, a construir y orientar, cosa que en el terreno del arte se constituye como una obligación.

\section{BIBLIOGRAFÍA}

ARÁN de Meriles, Pampa Olga

Nuevo diccionario de la teoría de Mijail Bajtin

Córdoba, Argentina, Ferreira, 2006.

BEZMALINOVIC, Fernanda

La revuelta edipica como especificidad latinoamericana en cuatro obras de Galemiri

Proyecto de Tesis para postular al grado de Magister en Literatura con Mención en Literatura Hispanoamericana y Chilena. Universidad de Chile, Departamento de Literatura, 2007.

DUJOVNE, León

Prólogo a Maimónides; Moisés ben Maimón: Guía de los descarriados

Tratado de teología y filosofia. Buenos Aires, S. Sigel, 1955, 3 v.

GALEMIRI, Benjamin

Antologia esencial

Santiago de Chile, Edebé- Editorial Don Bosco, 2003.

GALEMIRI, Benjamín

Mi vida como un tribunal. [En Línea] www.Galemiri.cl/bio.html [consulta: abril 2008] 
GUERRERO, Eduardo

Acto único. Dramaturgos en escena

Santiago de Chile, Ril Editores, 2001.

LETELIER, Agustín

Para leer a Galemiri.

En Benjamin Galemiri: El lobby del odio

Santiago de Chile, Galema, 2006.

MATAMALA Elorz, Roberto

Pedazos rotos de algo: La compleja enunciación en el drama de Escobar

Revista Apuntes (129): 2007.

MAIMÓNIDES, Moisés ben Maimón

Guia de los descarriados

Tratado de teología y filosofia. Buenos Aires, Editorial S. Sigel, 1955. 3 v.

OYARZÚN, Carola y otros

Las dramaturgias de Galemiri.

Teatral (2): 2000.

OYARZÚN, Carola

Benjamín Galemiri, territorio de la desmesura.

En Benjamín Galemiri: Infamante Electra. Ese discreto ego culpable

Santiago de Chile, Editorial Cuarto Propio, 2006.

THOMAS, Eduardo

Función de las didascalias en los textos dramáticos de Benjamin Galemiri.

Anales de Literatura Chilena (8): 2007. 